\title{
DEMANDA ENERGÉTICA NAS OPERAÇÕES MECANIZADAS NA SILAGEM DE MILHO NO SISTEMA DE "SILO BAG"'
}

\author{
ANDRÉ S. SEKI ${ }^{2}$, SÉRGIO H. BENEZ ${ }^{3}$, PAULO R. A. SILVA ${ }^{4}$, ÉLCIO H. YANO ${ }^{5}$, \\ LUIZ M. M. MELLO 6
}

\begin{abstract}
RESUMO: Foi avaliado o consumo energético das operações mecanizadas envolvidas na produção de silagem de planta inteira e silagem de "grão úmido" de milho, tendo como referência o processamento seco desse cereal. O ensaio foi conduzido na Fazenda Experimental Lageado, pertencente à Faculdade de Ciências Agronômicas, e nas instalações da Faculdade de Medicina Veterinária e Zootecnia - UNESP, localizada no município de Botucatu - SP. O delineamento experimental foi em blocos ao acaso, com parcelas subdivididas no tempo (três épocas de colheita: silagem de planta inteira, silagem de "grão úmido" e colheita de grãos secos), com 10 repetições. As análises estatísticas foram realizadas por meio do programa ESTAT, pelo teste de média de Tukey, a 5\% de probabilidade. A silagem de planta inteira teve o maior consumo de combustível por área. A secagem dos grãos de $15,5 \%$ para $13 \%$ foi responsável por $87 \%$ do gasto de energia por área. A silagem de "grão úmido" demandou o menor uso de energia por área nas operações mecanizadas.
\end{abstract}

PALAVRAS-CHAVE: consumo de energia, ensilagem, grão úmido.

\section{ENERGY DEMAND IN THE MECHANIZED OPERATIONS IN THE CORN SILAGE IN THE SILO BAG SYSTEM}

\begin{abstract}
This work aims to evaluate the energy consumption of the mechanized operations involved in the silage production of entire plant and silage of humid maize, having as reference the dry processing of this cereal. The experiment was on Lageado Experimental Farm of the Agronomy School, and the Education Research and Production Farm, of the Veterinary School of - UNESP São Paulo State University - Botucatu Campus. The experiment design was in randomized blocks with parts subdivided in time (three times of harvest: silage of entire plant, silage of humid grains and harvest of dry grains), with 10 repetitions. The statistical analyses were performed with ESTAT software, and Tukey test at $5 \%$ of probability. The highest fuel consumption per area was reported for the ensilage of entire plant. The highest energy demand per area was reported for the processing of dry grain, as drying is responsible for $87 \%$ of the energy expense. The ensilage of humid grain demanded the lesser use of energy per area in the mechanized operations.
\end{abstract}

KEYWORDS: energy consumption, ensilage, humid grains.

\section{INTRODUÇÃO}

A crescente necessidade de racionalização de energia dos sistemas e das operações agrícolas fez com que se desenvolvessem trabalhos de pesquisa visando à obtenção de melhores técnicas e métodos e à redução no consumo de energia embutidos nos insumos e combustíveis consumidos, além de melhor conservação do solo e dos recursos naturais (MIALHE, 1996).

\footnotetext{
${ }^{1}$ Extraído da dissertação de mestrado do primeiro autor.

${ }^{2}$ Engo ${ }^{\circ}$ Agrônomo, Doutorando do Programa de Pós-Graduação em Energia na Agricultura, UNESP, Botucatu - SP, Fone: (0XX14) 3811-7165, aseki@fca.unesp.br

${ }^{3}$ Prof. Titular, Departamento de Engenharia Rural, UNESP, Botucatu - SP, benez@ fca.unesp.br

${ }^{4}$ Prof. Doutor, Departamento de Engenharia Rural, UNESP, Botucatu - SP, arbex@ fca.unesp.br

${ }^{5}$ Prof.Doutor, UNESP, Registro - SP, ehyano@ registro.unesp.br

${ }^{6}$ Prof. Doutor, Departamento de Fitossanidade, Engenharia Rural e Solos, UNESP, Ilha Solteira - SP, malcolm@agr.feis.unesp.br Recebido pelo Conselho Editorial em: 16-5-2008

Aprovado pelo Conselho Editorial em: 16-5-2009
} 
Uma das maiores preocupações dos agricultores tem sido o custo da energia consumida nas operações das máquinas e dos equipamentos agrícolas, que pode ser reduzido por meio de melhores projetos de máquinas e de implementos e melhores procedimentos operacionais (STANGE et al., 1984). Segundo SEKI (2007), o alto custo dos combustíveis e das máquinas agrícolas e a baixa remuneração do produtor exigem o uso de técnicas de gerenciamento dos serviços, principalmente aquelas ligadas às operações motomecanizadas, visando à minimização do consumo de energia.

O uso do sistema de plantio direto nas principais culturas em sucessão tem possibilitado receita extra ao agricultor, uma vez que gera ganho de tempo no momento da semeadura, na manutenção dos teores de água no solo, na possibilidade de fornecer cobertura vegetal no período de entressafra e na economia de até $70 \%$ de combustível em relação ao preparo convencional (MARQUES, 1999).

Na produção de grãos, a operação de secagem pode representar até $50 \%$ do consumo total de energia, no caso específico do milho. Apesar de haver, à disposição do usuário, equipamentos para o controle de processos, a tomada de decisão para a otimização de uma determinada operação cabe ao operador. As operações de secagem e de armazenamento, quando conduzidas corretamente e com equipamentos eficientes, contribuem significativamente para a redução dos custos operacionais, em razão da economia de energia que propiciam (LOPES et al., 2000).

A antecipação da colheita como prática para a economia de energia na secagem, recomendada por alguns fabricantes de secadores, para demonstrar a eficiência de seus produtos quando secam grãos com alto teor de água inicial, reduz as perdas no campo, mas traz como inconveniente o consumo adicional de energia com a secagem dos grãos com alto teor de água. A necessidade de liberação do campo para novos plantios ou a melhor qualidade do produto colhido antecipadamente são as principais vantagens e, na maioria dos casos, pode compensar o gasto de energia na secagem.

Uma forma de minimizar e racionalizar a utilização da energia nos processos agrícolas, principalmente na destinação final dos produtos, como grãos de milho, pode ser a silagem de "grão úmido", que surge como alternativa para o produtor, na qual o processo de secagem é substituído pela moagem e armazenamento em alta densidade com altos teores de água (COSTA, 2001).

As silagens de milho surgem como opção para o produtor, visto que a conservação do milho para a alimentação animal na forma de silagem de "grão úmido" pode ser até $11 \%$ mais econômica em relação aos grãos secos, por eliminar as etapas de limpeza e secagem do processamento de grãos (COSTA et al., 1998).

Com base no exposto, o objetivo do trabalho foi avaliar o consumo energético das operações mecanizadas envolvidas na produção de silagem de milho no sistema de "silo bag" (silagem de planta inteira e "grão úmido"), tendo como referência o processamento seco desse cereal cultivado em sistema de plantio direto.

\section{MATERIAL E MÉTODOS}

O ensaio foi conduzido na Fazenda Experimental Lageado, pertencente à Faculdade de Ciências Agronômicas - UNESP, localizada no município de Botucatu - SP, no ano agrícola de 2005/2006. O processo de ensilagem foi conduzido na instalação pertencente à Faculdade de Medicina Veterinária e Zootecnia - UNESP, Câmpus de Botucatu - SP.

O solo da área experimental foi classificado como NITOSSOLO VERMELHO distroférrico (EMBRAPA, 1999). Após a colheita da soja (2004/2005), implantou-se a cultura do triticale, na qual, após a colheita das plantas existentes na área, realizou-se a dessecação por meio de herbicida (Glyfosate), na dosagem de $2,5 \mathrm{~kg} \mathrm{ha}^{-1}$ (p.c.), para a instalação do experimento. Foram utilizadas sementes de milho híbrido DKB 466, material esse pertencente à empresa Dekalb, com poder germinativo de $93 \%$ e $99 \%$ de pureza. Obteve-se a produtividade média, por meio de amostragens realizadas dentro das parcelas experimentais, de 13.020 e $7.052 \mathrm{~kg} \mathrm{ha}^{-1}$ de matéria seca e de grãos de milho, respectivamente. 
O delineamento experimental utilizado foi em blocos ao acaso, com parcelas subdivididas no tempo (três épocas de colheita: silagem de planta inteira (113 dias após a emergência), silagem de "grão úmido" (147 dias após a emergência) e colheita de grãos secos (170 dias após a emergência)), com dez repetições. Cada parcela experimental possuía $50 \mathrm{~m}$ de comprimento e $10 \mathrm{~m}$ de largura, perfazendo área de $500 \mathrm{~m}^{2}$.

Nas operações de semeadura e de transporte, foi utilizado trator da marca John Deere, modelo 6600 (4x2 TDA), com potência nominal de 89 kW (121 cv); já para as operações de pulverização, adubação de cobertura, colheita da forragem e ensilagem do milho no sistema de "silo bag", foi utilizado trator da marca Massey Ferguson, modelo MF 283 (4×2 TDA), com potência nominal de $63,2 \mathrm{~kW}(86 \mathrm{cv})$.

Os equipamentos utilizados para a instalação e os tratos culturais do milho foram idênticos nos tratamentos, utilizando: pulverizador de barras marca Jacto, modelo Condor; semeadora-adubadora, marca Marchesan, modelo PST2, de arrasto, com quatro unidades de semeadura espaçadas de 0,86 m; cultivador-adubador para aplicação de fertilizantes em cobertura para plantio direto, marca Marchesan, modelo CPD-4/2.

$\mathrm{Na}$ produção de silagem de planta inteira, foram utilizados os seguintes equipamentos: colhedora de forragem marca JF Máquinas, modelo JF92 Z10; carreta agrícola marca Casa Grande, modelo quatro rodas; ensiladora com sistema de compactação por rosca sem fim, marca Boelter, modelo Silo Press SP20, com acessórios para forragem.

Para a produção de silagem de "grão úmido", foram utilizados os equipamentos: colhedora autopropelida de grãos, marca Massey Ferguson, modelo MF 3640, tração traseira auxiliar, com potência nominal de 95,6 kW (130 cv); carreta basculante marca Stara, modelo Reboke 5000; ensiladora com sistema de compactação por rosca sem fim, marca Boelter, modelo Silo Press SP20, com acessórios para grãos.

$\mathrm{Na}$ produção de grãos secos, foram utilizados os seguintes equipamentos: colhedora autopropelida de grãos, marca Massey Ferguson, modelo MF 3640, tração traseira auxiliar, com potência nominal de 95,6 kW (130 cv); carreta basculante marca Stara, modelo Reboke 5000.

Os parâmetros avaliados foram: força média na barra, torque na TDP, rotação na TDP, velocidade de deslocamento e consumo horário de combustível.

Para a aquisição de dados, utilizou-se de sistema de aquisição digital "micrologger 21X, marca Campbell Scientific", para monitorar e exibir os dados da célula de carga, torciômetro e do gerador de impulso (fluxômetro). Os dados foram armazenados continuamente em módulo de armazenamento externo de dados "Storage module SM196". O monitoramento da velocidade foi realizado indiretamente por meio da frequência de aquisição de dados de $10 \mathrm{~Hz}$ do "micrologger $21 X "$ em relação ao deslocamento dos conjuntos mecanizados.

Para a determinação da força de tração requerida pelos equipamentos de arrasto e pelos sistemas de comboio, utilizou-se de célula de carga da marca Sodmex, modelo N-400, com capacidade de $50 \mathrm{kN}$ e sensibilidade de $2,001 \mathrm{mV} / \mathrm{V}$. O torque na tomada de potência (TDP) dos equipamentos acionados por esses dispositivos foi determinado utilizando-se de torciômetro marca Sodmex, modelo MT-202, de extensômetros de resistência elétrica, com escala nominal de 0 a $3.000 \mathrm{Nm}$, com sensibilidade de $1,994 \mathrm{MV} \mathrm{V}^{-1}$. Para a determinação da rotação da TDP, foi utilizado um sensor fotoelétrico mecânico, constituído de fotocélulas, disco ranhurado com 60 ranhuras, indicador instantâneo de rotação, integrador de rotação e cronômetro conjugado, possibilitando indicação da rotação na forma instantânea e integrada.

Para quantificar o consumo de combustível, utilizou-se um fluxômetro, marca "Flowmate" oval, modelo Oval M-III, que emitia ao sistema de aquisição de dados uma unidade de pulso a cada $\mathrm{mL}$ de combustível que passava pelo mesmo. O consumo operacional de combustível foi 
determinado por meio da relação entre o consumo horário de combustível e a capacidade de campo efetiva.

A capacidade de campo efetiva foi determinada pela relação entre a área útil da parcela trabalhada e o tempo gasto no percurso da parcela. A potência média exigida na barra de tração foi obtida por meio do produto entre a força e a velocidade média. A potência na TDP foi calculada pela eq.(1):

$$
\mathrm{P}_{\mathrm{TDP}}=\mathrm{T}_{\mathrm{m}} \text { n } 0,00010466
$$

em que,

$\mathrm{P}_{\mathrm{TDP}}$ - potência média na TDP, $\mathrm{kW}$;

$\mathrm{T}_{\mathrm{m}}$ - torque médio da TDP, Nm;

$\mathrm{n}$ - rotação na TDP do trator, e

0,00010466 - fator de conversão.

A potência demandada na operação de colheita do milho ("grão úmido" e seco), por intermédio de colhedoras automotrizes, foi determinada a partir do consumo horário de combustível, por meio das potências teóricas e efetivas (MIALHE, 1974).

A potência teórica, resultante da transformação total da energia interna do combustível em trabalho mecânico, foi determinada por meio da eq.(2):

$$
\mathrm{Pt}=\frac{\mathrm{CCh} 0,85210110427}{360075}
$$

em que,

Pt -potência teórica, cv;

CCh - consumo horário de combustível, $\mathrm{L} \mathrm{h}^{-1}$;

0,852 - massa específica do combustível, $\mathrm{kg} \mathrm{L}^{-1}$ (MIALHE, 1980);

10110 - poder calorífico do combustível, $\mathrm{kcal} \mathrm{kg}^{-1}$ (MIALHE, 1980);

427 - equivalente mecânico do calor, $\mathrm{kgm} \mathrm{kcal}^{-1}$;

3600 - fator de conversão, e

75 - fator de conversão.

A potência efetiva foi calculada pela eq.(3):

$$
\mathrm{Pe}=\frac{(0,34 \mathrm{Pt})}{1,36}
$$

em que,

Pe - potência efetiva, kW;

Pt - potência teórica, cv;

0,34 - rendimento térmico mecânico (MIALHE, 1980), e

1,36 - fator de conversão.

O gasto energético durante o processo de secagem a alta temperatura dos grãos de milho (15,5\% para $13 \%$ de água) foi estimado conforme eq.(4):

Ges $=1,25 \mathrm{Ar}$

em que,

Ges - gasto energético na secagem, $\mathrm{kWh} \mathrm{t}^{-1}$;

1,25 - energia requerida por quilograma de água removida, $\mathrm{kWh} \mathrm{kg}^{-1}$ (GUNASEKARAN, 2002), e

$\mathrm{Ar}$ - água removida por tonelada de grãos, $\mathrm{kg} \mathrm{t}^{-1}$.

O consumo específico de energia por área foi calculado por: 
em que,

Uea $=\mathrm{Pm}$ Td $\quad$ ou $\quad$ Uea $=$ Ges Prod

Uea - consumo específico de energia por área, $\mathrm{kWh} \mathrm{ha}^{-1}$;

Pm - potência na barra de tração, $\mathrm{kW}$;

$\mathrm{Td}$ - tempo efetivo demandado, $\mathrm{h} \mathrm{ha}^{-1}$;

Ges - gasto energético na secagem, $\mathrm{kW} \mathrm{h} \mathrm{t}^{-1}$, e

Prod - produtividade de grãos, $\mathrm{t} \mathrm{ha}^{-1}$.

Para os dados coletados, a somatória das médias das repetições de consumo de combustível por área e o uso específico de energia por área, nas operações realizadas nos tratamentos, foram analisados pelo teste de Tukey, a 5\% de probabilidade. As análises estatísticas foram realizadas por intermédio do programa ESTAT (1992).

\section{RESULTADOS E DISCUSSÃO}

Os valores totais da energia demandada nas operações mecanizadas, nos diferentes processos da cadeia produtiva da cultura do milho, tais como a capacidade operacional efetiva, o consumo horário de combustível, o consumo de combustível por área e a demanda de energia por área são apresentados na Tabela 1 .

TABELA 1. Valores médios da capacidade operacional efetiva - CE (ha $\mathrm{h}^{-1}$ ), consumo horário de combustível - CCh $\left(\mathrm{L} \mathrm{h}^{-1}\right)$, consumo de combustível por área - $\mathrm{CCa}\left(\mathrm{L} \mathrm{ha}^{-1}\right)$ e uso específico de energia por área - UEA $\left(\mathrm{kWh} \mathrm{ha}^{-1}\right)$, nas operações realizadas no experimento. Average values of effective operational capability - EC $\left(\mathbf{h ~ h}^{-1}\right)$, hourly consumption of fuel - CCh $\left(\mathrm{L} \mathrm{h}^{-1}\right)$, consumption of fuel per area - CCa $\left(L h^{-1}\right)$ and specific energy use per area - UEA $\left(k_{W h ~ h} h^{-1}\right)$, operations performed in the experiment.

\begin{tabular}{|c|c|c|c|c|}
\hline Operação & $\begin{array}{c}\mathrm{CE} \\
\left(\mathrm{ha} \mathrm{h}^{-1}\right)\end{array}$ & $\begin{array}{c}\mathrm{CCh} \\
\left(\mathrm{L} \mathrm{h}^{-1}\right)\end{array}$ & $\begin{array}{c}\mathrm{CCa} \\
\left(\mathrm{L} \mathrm{ha}^{-1}\right)\end{array}$ & $\begin{array}{c}\text { UEA } \\
\left(\mathrm{kWh} \mathrm{ha}^{-1}\right)\end{array}$ \\
\hline \multicolumn{5}{|l|}{ Silagem de planta inteira } \\
\hline Implantação & - & - & 8,84 & 8,53 \\
\hline Colhedora de Forragem & 0,21 & 7,40 & 34,25 & 96,43 \\
\hline Transporte da silagem de planta inteira & 1,42 & 10,59 & 7,43 & 6,01 \\
\hline Ensilagem de planta inteira & 0,36 & 7,72 & 21,75 & 74,31 \\
\hline Total & - & - & $72,27 \mathrm{~A}$ & $185,28 \mathrm{~B}$ \\
\hline \multicolumn{5}{|l|}{ Silagem de grãos úmido } \\
\hline Implantação & - & - & 8,84 & 8,53 \\
\hline Colheita do grão úmido & 1,12 & 15,31 & 13,59 & 46,52 \\
\hline Transporte do grão úmido & 5,97 & 10,75 & 1,80 & 1,60 \\
\hline Ensilagem de grão úmido & 2,02 & 8,51 & 4,23 & 13,93 \\
\hline Total & - & - & $28,46 \mathrm{~B}$ & $70,58 \mathrm{C}$ \\
\hline \multicolumn{5}{|l|}{ Grão seco } \\
\hline Implantação & - & - & 8,84 & 8,53 \\
\hline Colheita do grão seco & 1,25 & 12,64 & 10,14 & 34,56 \\
\hline Transporte do grão seco & 7,12 & 10,83 & 1,52 & 1,67 \\
\hline Processo de secagem & - & - & - & 250,70 \\
\hline Total & - & - & $20,50 \mathrm{C}$ & $295,46 \mathrm{~A}$ \\
\hline DMS (Tukey 5\%) & - & - & 2,00 & 8,82 \\
\hline C.V. $(\%)$ & & & 3,84 & 3,86 \\
\hline
\end{tabular}


Os valores médios de consumo total de combustível por área, nas diferentes operações mecanizadas realizadas nas três épocas e formas diferentes de colheita da cultura do milho (Tabela 1), apresentaram diferenças significativas, nos quais a produção da silagem de planta inteira apresentou consumo de combustível por área 60 e $70 \%$ superior aos da silagem de "grão úmido" e processamento do milho seco, respectivamente.

Esse maior valor é justificado pela baixa capacidade operacional da colhedora de forragem utilizada na operação, explicada à menor largura útil desse equipamento, obrigando o conjunto a dar maior número de voltas na área, demandando mais combustível, visto que $46 \%$ do consumo de combustível por área, nesse caso, foram gastos nessa operação. Os outros $54 \%$ foram gastos na implantação, tratos culturais e no processo de ensilagem das plantas de milho no sistema de "silo bag".

O consumo específico total de energia por área apresentou diferenças estatísticas entre as diferentes formas de colheita, e a colheita do grão seco do milho apresentou os maiores valores, sendo 35 a 75\% superior à da silagem de planta inteira e silagem de "grão úmido", respectivamente.

O consumo demasiado de energia por área requerida pela colheita do grão seco do milho é representado pelo consumo de energia durante o processo de secagem, consumindo $250 \mathrm{kWh} \mathrm{ha}^{-1}$ $(87 \%)$ do total de energia gasta nesse processo. Valores esses superiores aos obtido por SILVA (1997), que verificou consumo no processamento de secagem de $60 \%$ do total de energia utilizada na cadeia produtiva dos grãos de milho. Além de que, a secagem de grãos de milho com baixos teores de água (15,5\%) para os recomendados para o armazenamento (13\%), a demanda de energia é maior devido a baixas eficiências na retirada de água dos grãos pelos equipamentos de secagem.

Entretanto, segundo BROOKER et al. (1992), quando o ar de secagem é indiretamente aquecido por meio de combustíveis fósseis, a energia gasta com a etapa de secagem pode alcançar $80 \%$ do gasto total de energia para o pré-processamento dos produtos.

A demanda total de energia na obtenção do grão seco, desde a dessecação da vegetação até a secagem do mesmo, foi de $287 \mathrm{kWh} \mathrm{ha}^{-1}$; desse total, o sistema de plantio direto consumiu $10 \mathrm{kWh} \mathrm{ha}^{-1}(4 \%)$, desde a dessecação até os tratos culturais. Por outro lado, MARQUES (1999), mensurando o consumo específico de energia por área no preparo convencional do solo para a implantação da cultura do milho, por meio de duas gradagens, obteve o valor de $60 \mathrm{kWh} \mathrm{ha}^{-1}$, isto é, seis vezes superior ao obtido no sistema de plantio direto utilizado.

$\mathrm{Na}$ silagem de planta inteira de milho, o uso específico de energia por área diferiu estatisticamente da cadeia da silagem de "grão úmido", apresentando maiores valores. A operação da colheita da silagem de planta inteira representou aproximadamente $96 \mathrm{kWh} \mathrm{ha}^{-1}(50 \%)$ da energia total utilizada por área e outros $74 \mathrm{kWh} \mathrm{ha}^{-1}(40 \%)$ da energia total por área, na operação de ensilagem no sistema "silo bag".

A silagem de "grão úmido" apresentou o menor valor do uso de energia por área, e a operação de colheita requisitou a maior demanda de energia por área $45 \mathrm{kWh} \mathrm{ha}^{-1}(65 \%)$ do total, outros $15 \mathrm{kWh} \mathrm{ha}^{-1}(20 \%)$ foram gastos na operação de ensilagem dos grãos úmidos de milho. O alto teor de água nos grãos reduz a capacidade de trabalho da colhedora, bem como danos aos grãos de milho, favorecendo nos processos fermentativos da silagem de grãos úmidos.

\section{CONCLUSÕES}

A silagem de planta inteira teve o maior consumo de combustível por área, e a silagem de "grão úmido" demandou o menor uso de energia por área nas operações mecanizadas. A silagem de planta inteira permite ao produtor antecipar em 63 dias o plantio da cultura sucessora e a maximização da utilização da terra, mesmo em condições edafoclimáticas desfavoráveis. A secagem dos grãos de $15,5 \%$ para $13 \%$ foi responsável por $87 \%$ do gasto de energia por área. 


\section{REFERÊNCIAS}

BROOKER, D.B.; BAKKER-ARKEMA, F.W.; HALL, C.W. Drying and storage of grains and oilseeds. Westport: AVI, 1992. 450 p.

COSTA, C.; ARRIGONI, M.D.B.; SILVEIRA, A.C. Custos de silagem de grãos úmidos de milho. Boletim do Leite, Piracicaba, v.5, n.51, p.2, 1998.

COSTA, C. Valor alimentício e aspectos econômicos de volumosos e de grãos de milho ensilado e seco no confinamento de bovinos criados no sistema superprecoce. 2001. $69 \mathrm{f}$. Tese (Livre-Docência) - Faculdade de Medicina Veterinária e Zootecnia, Universidade Estadual Paulista, Botucatu, 2001.

EMBRAPA. EMPRESA BRASILEIRA DE PESQUISA AGROPECUÁRIA. Sistema brasileiro de classificação de solos. Rio de Janeiro, 1999. 412 p.

ESTAT 2.0. Sistema de análise estatística. Jaboticabal: Departamento de Ciências Exatas, FCAV, UNESP, 1992. 1 Disquete.

GUNASEKARAN, S. Optimal energy management in grain drying. Critical Reviews in Food Science and Nutrition, Newark, v.25, n.1, p.1-48, 2002.

LOPES, R.P.; AFONSO, A.D.L.; SILVA, J.S. Energia no pré-processamento de produtos agrícolas. In: __ Secagem e armazenamento de produtos agrícolas. Viçosa - MG: UFV, 2000. 1 CD-ROM.

MARQUES, J.P. Manejo da vegetação espontânea para implantação da cultura do milho (Zea mays L.) em plantio direto e preparo convencional do solo. 1999. 98 f. Dissertação (Mestrado em Energia na Agricultura) - Faculdade de Ciências Agronômicas, Universidade Estadual Paulista, Botucatu, 1999.

MIALHE, L.G. Manual de mecanização agrícola. São Paulo: Ceres, 1974. 301 p.

MIALHE, L.G. Máquinas motoras na agricultura. São Paulo: Ed. da Universidade de São Paulo, 1980. v.1, 289 p.

MIALHE, L.G. Máquinas agrícolas ensaios e certificação. Piracicaba: FEALQ, USP, 1996. 722 p.

SEKI, A. S. Demanda energética no processo de ensilagem de milho. 2007.101 f. Dissertação

(Mestrado em Energia na Agricultura) - Faculdade de Ciências Agronômicas, Universidade Estadual Paulista, Botucatu, 2007.

SILVA, J.S. Armazenamento de grãos na fazenda. Tecnologia e Treinamento Agropecuário, Viçosa - MG, v.2, n.5, p.27, 1997.

STANGE, K.; CHRISTIANSON, L.L.; THORESON, B.; ALCOOCK, R.; VIK, B. Microcomputer goes to the field to gather tractor test data. Agricultural engineering, St. Joseph, v.65, n.1, p.21-26, 1984. 